\title{
Quadragésimo ano do parecer CFE no 977/65
}

\author{
Carlos Roberto Jamil Cury
}

Pontifícia Universidade Católica de Minas Gerais, Mestrado em Educação

Em nosso entender, um programa eficiente de estudos pós-graduados é condição básica para conferir à nossa universidade caráter verdadeiramente universitário, para que deixe de ser instituição apenas formadora de profissionais e se transforme em centro criador de ciência e cultura.

Parecer CFE $n^{\circ}$ 977/65

\section{Antecedentes}

A qualificação de professores e de pesquisadores de um país de formação colonial peculiar, que não estimulou a formação autóctone de intelectuais e pesquisadores, de seletividade sociopolítica que excluiu contingentes humanos enormes, gerou impedimentos estruturais para uma afirmação autônoma e ampliada

${ }^{1}$ Documenta $\mathrm{n}^{\circ}$ 44, dez., 1966, p. 67-88. Para facilitar o leitor, usarei essa forma na referência de todos os documentos oficiais citados neste artigo, de preferência indicando a fonte mais acessível na qual foi publicado. do ensino superior. Por isso, quando as condições internas permitiram uma formação mais abrangente, a capacidade externa serviu de referência para criar um sistema autônomo de pós-graduação, especialmente para a capacitação de um corpo docente qualificado e titulado. À competência adquirida no exterior somavase aquela já conseguida dentro do próprio país, e tinhase, então, como resultado, a ampliação do número de pesquisadores e professores dentro Brasil. Esse corpo docente constituir-se-ia na "massa crítica” que daria suporte humano à criação do sistema. Pode-se dizer que a consolidação do sistema de pós-graduação no Brasil, desde o final dos anos de 1960, contou também com o investimento consciente, propiciado pelo Estado, em matéria de capacidade adquirida no exterior.

Mas, para aí se chegar, um longo processo deveria ser trilhado. E o primeiro marco específico desse itinerário situa-se nos anos trinta do século passado. Em 1931, Francisco Campos, à época ministro da Educação e Saúde Pública do Governo Provisório de Getúlio Vargas, por meio do decreto $n^{0} 19.851$, de abril de 1931 (apud Fávero, 2000a), impunha a “investigação científica em quaisquer domínios dos co- 
nhecimentos humanos" (art. $1^{\circ}$ ) como finalidade do ensino universitário. Esse decreto institucionaliza também cursos de aperfeiçoamento e de especialização como forma de aprofundamento de conhecimentos profissionais e científicos. No art. 32 diz-se que "nos institutos universitários será atendido a um tempo o duplo objetivo de ministrar o ensino eficiente dos conhecimentos humanos adquiridos e de estimular o espírito de investigação original, indispensável ao progresso das ciências”. O decreto também previa um Museu Social (art. 110) como lugar congregador de informação e de pesquisas voltadas para os problemas nacionais. O título de doutor, expresso no art. 90, devia se apoiar em uma tese, do que resultaria tanto a expedição de um diploma quanto a assinalação de uma dignidade honorífica (p. 51-83).

Ainda nos mesmos anos de 1930, a então Universidade de Minas Gerais (futura UFMG) cria seu doutorado em direito, e é criada a Universidade de São Paulo (USP), com forte presença de intelectuais franceses que auxiliaram na implantação desta prestigiosa universidade estadual, com destaque para a abertura dos cursos e para a inovação de métodos e técnicas de investigação científica.

No Manifesto da Fundação da Escola de Sociologia e Política de São Paulo, em 1933, lamenta-se como lacuna na reorganização da vida do país a inexistência de uma elite numerosa e organizada, instruída sob métodos científicos, a par das instituições e conquistas do mundo civilizado (apud Fávero, 2000b, p. 199). A escola propõe-se a contratar "professores de renome fora do país e [manter] intercâmbio com instituições estrangeiras análogas...” (idem, p. 200). Segundo esse manifesto, "não há exemplo de civilização alguma que não tivesse por alicerce elites intelectuais sábias e poderosamente construídas” (idem, ibidem). Em 1941, esta escola é instalada e abre-se nela um curso de mestrado, com a presença e o apoio de pesquisadores norte-americanos.

Em 1946, o decreto $\mathrm{n}^{\circ}$ 21.321, de 18 de junho, aprovou o Estatuto da Universidade do Brasil (Fávero, 2000a, p. 159-195). Em seu art. 71, reconhece a existência de cursos de pós-graduação, cuja finalidade se destina à especialização profissional, ficando os cursos de doutorado a critério do regimento da universidade. Diz o art. 76: “Os cursos de pós-graduação, destinados aos diplomados, terão por fim especial a formação sistemática de especialização profissional, de acordo com o que for estabelecido pelo regimento”.

Já o art. 77 afirma: “Os cursos de doutorado serão criados pelas escolas e faculdades e definidos nos respectivos regimentos, segundo conveniências específicas”. E o art. 119 afirma que, em casos especiais, um professor catedrático ou adjunto terá dispensa temporária, até um ano, “a fim de que se devote à pesquisa em assuntos de sua especialidade, no país ou no estrangeiro".

Em 1949, o presidente Dutra encaminha ao Congresso o projeto de lei elaborado por uma comissão cujo presidente era o almirante Álvaro Alberto, propondo a criação de um Conselho Nacional de Pesquisa (CNP). Esse conselho foi criado pela lei $\mathrm{n}^{\circ} 1.310 / 51{ }^{2}$ que no art. $3^{\circ}$ diz explicitamente que a ele compete:

a) promover investigações científicas e tecnológicas por iniciativa própria, ou em colaboração com outras instituições no país ou no exterior;

b) auxiliar a formação e o aperfeiçoamento de pesquisadores e técnicos, organizando ou cooperando na organização de cursos especializados, sob a orientação de professores nacionais ou estrangeiros, concedendo bolsas de estudo ou de pesquisa e promovendo estágios em instituições técnico-científicas e em estabelecimentos industriais no país ou no exterior;

c) manter-se em relação com instituições nacionais ou estrangeiras para intercâmbio de documentação técnico-científica e participação nas reuniões e congressos, promovidos no país ou no exterior, para estudo de temas de interesse comum.

Esse conselho, conhecido hoje como Conselho Nacional de Desenvolvimento Científico e Tecnoló-

${ }^{2}$ Disponível em: <http://www4.prossiga.br/lopes/ing/traj/lei/ lei1310-01.html>. Acesso em: maio de 2005. 
gico (CNPq), dá grande sustentação à formação de pesquisadores e estudiosos em todas as áreas do conhecimento, com vasto número de programas, auxílios e investimentos.

Nos anos de 1950 e de 1960 havia uma forte corrente que defendia o doutorado como forma regular e institucionalizada de se criar um corpo permanente de cientistas no país (Carvalho, 1992). Cumpre registrar que em 1952 o Brasil firmou um acordo com os Estados Unidos pelo qual se celebraram diversos convênios entre universidades. Assim, muitos estudantes foram para os Estados Unidos a fim de fazer mestrado ou doutorado. E muitos professores norte-americanos vieram para o Brasil a fim de desenvolver programas de pós-graduação.

Em 1951, decola a iniciativa de Anísio Teixeira, criando, junto ao Ministério da Educação e Saúde, a Campanha de Aperfeiçoamento do Pessoal de Nível Superior (CAPES), pelo decreto $\mathrm{n}^{\circ}$ 29.741, de 11/6/ 1951, ${ }^{3}$ assinado por Getúlio Vargas e Simões Filho. A CAPES, até hoje, dá grande suporte às instituições formadoras de docentes e de pesquisadores. Apesar disso, antes da consolidação das universidades públicas federais e estaduais, nos anos de 1950 e de 1960, segundo Beiguelman (1997, p. 34):

Eram poucas as universidades brasileiras onde era possível a realização de estudos de pós-graduação, além do que, nessa época, a pós-graduação brasileira, por seguir o modelo francês antigo, visava apenas ao título de Doutor. Não havia o Mestrado entre nós, e o título de Doutor, alcançado de modo exageradamente artesanal, era ostentado por um número muito reduzido de pessoas.

A criação específica da pós-graduação teve um dos seus momentos mais significativos na fundação da Universidade de Brasília (UnB), pela lei no 3.998, de 15 de dezembro de $1961 .{ }^{4}$ Nessa universidade, a

${ }^{3}$ Publicado no Diário Oficial de 13/7/1951

${ }^{4}$ Disponível em: <http://www.unb.br/fub/lei3998.htm>. Acesso em: maio de 2005. pós-graduação tornou-se uma atividade institucional. Pode-se ler no art. $9^{\circ}$ dessa lei:

A Universidade será uma unidade orgânica integrada por Institutos Centrais de Ensino e de Pesquisa e por Faculdades destinadas à formação profissional, cabendo:

I - Aos Institutos Centrais, na sua esfera de competência:

a) ministrar cursos básicos, de ciências, letras e artes;

b) formar pesquisadores e especialistas; $\mathrm{e}$

c) dar cursos de pós-graduação e realizar pesquisas e estudos nas respectivas especialidades.

II - As Faculdades, na sua esfera de competência:

a) ministrar cursos de graduação para formação profissional e técnica;

b) ministrar cursos de especialização e de pós-graduação;

c) realizar pesquisas e estudos nos respectivos campos de aplicação científica, tecnológica e cultural.

Em 30 de setembro de 1964, o decreto n ${ }^{\circ} 54.356,{ }^{5}$ assinado pelo presidente Castelo Branco e pelo ministro Flávio Suplicy Lacerda, dispõe sobre a atual Coordenação do Aperfeiçoamento de Pessoal de Nível Superior, vinculada ao Ministério da Educação (MEC). Nesse decreto vê-se que, entre os objetivos da CAPES, está a concessão de bolsas a graduados para estudos no país e no estrangeiro. Conforme Martins (1991, p. 94):

O desenvolvimento do sistema nacional de programas de mestrado e doutorado tem seu ponto de partida de aceleração em fins da década dos anos 60, dentro de um quadro que, moldado pelo movimento revolucionário de 1964, estabeleceu uma nova ordem política que, por ações rápidas e efetivas, pretendia apresentar resultados que justificassem sua implantação, particularmente no domínio econômico.

\footnotetext{
${ }^{5}$ Publicado no Diário Oficial de 30/11/1964 e na Documen-
} ta $\mathrm{n}^{\circ}$ 31, nov., 1964, p. 113-118. 
Em 1982, o decreto $\mathrm{n}^{\circ}$ 86.816, de 5/1/1982, ${ }^{6}$ alterou as funções da CAPES, cuja estrutura básica ficou mantida até os dias atuais. Entre outras finalidades da CAPES expressas nesse decreto, consta:

II - elaborar o Plano Nacional de Pós-Graduação bem como acompanhar e coordenar a sua execução; [...]

V - acompanhar e avaliar os cursos de pós-graduação

e a interação entre ensino e pesquisa; [...]

VIII - manter intercâmbio e contato com outros órgãos da administrarão pública ou com entidades privadas, inclusive internacionais ou estrangeiras, visando à celebração de convênios, acordos, contratos e ajustes relativos à pós-graduação e aperfeiçoamento de pessoal de nível superior, obedecidas as diretrizes estabelecidas pela Secretaria Geral do MEC, relativas aos assuntos internacionais;

Uma das razões do sucesso da política de pósgraduação deve-se a essa continuidade aperfeiçoada, que sempre contou com o fomento do Estado e com o apoio e a participação da comunidade científica. A única tentativa de destruir a CAPES deu-se no desastrado Governo Collor.

\section{A pós-graduação no Brasil: do parecer CFE $n^{\circ}$ 977/65 aos dias atuais}

O ano de 2005 registra o quadragésimo ano do parecer n ${ }^{\circ}$ 977, de 3 dezembro de 1965, do então CFE. Exarado pela Câmara de Ensino Superior (CES) daquele conselho, teve como relator o conselheiro Newton Sucupira.

Esse parecer tem como objeto a definição da pósgraduação, seus níveis e suas finalidades. Além do relator, o parecer foi assinado por nomes altamente significativos da CES, todos bons conhecedores da educação nacional: Clóvis Salgado, José Barreto Filho, Maurício Rocha e Silva, Durmeval Trigueiro Mendes, Alceu Amoroso Lima, Anísio Teixeira, Valnir Chagas e Rubens Maciel. Era presidente dessa câmara o conselheiro Antônio Ferreira de Almeida Júnior.

\footnotetext{
${ }^{6}$ Publicado no Diário Oficial de 6/1/1982.
}

Pode-se afirmar que, do ponto de vista doutrinário, em matéria oficial, esse parecer continua sendo a grande, senão a única referência sistemática da pósgraduação em nosso país.

A iniciativa próxima relativa ao parecer nasceu de um aviso ${ }^{7}$ do então ministro da Educação e Cultura, Flávio Suplicy de Lacerda (15/4/1964 a 10/6/1966), no Governo Castelo Branco. Por esse aviso, o ministro solicita ao CFE um pronunciamento, em vista da "necessidade de implantar e desenvolver o regime de cursos de pós-graduação em nosso ensino superior”, cuja institucionalização e regulamentação viria superar "a imprecisão, que reina entre nós, sobre a natureza desses cursos".

O parecer CFE n ${ }^{\circ}$ 977/65, tendo sido homologado pelo ministro da Educação em 6/1/1966 e publicado no Diário Oficial da União em 20/1/1966, passou a conceituar e normatizar os cursos de pós-graduação no Brasil.

O parecer apóia-se inicialmente no art. 69 da lei $n^{\circ} 4.024$, de 20/12/1961 (LDB):

Art. 69. Nos estabelecimentos de ensino superior podem ser ministrados os seguintes cursos:

a) de graduação, abertos à matrícula de candidatos que hajam concluído o ciclo colegial ou equivalente, e obtido classificação em concurso de habilitação;

b) de pós-graduação, abertos a matrícula de candidatos que hajam concluído o curso de graduação e obtido o respectivo diploma;

c) de especialização, aperfeiçoamento e extensão, ou quaisquer outros, a juízo do respectivo instituto de ensino, abertos a candidatos com o preparo e os requisitos que vierem a ser exigidos.

Entretanto, entendendo que o artigo 70 da LDB só dava competência ao CFE para regulamentar cursos superiores que habilitassem os formandos com diplomas asseguradores de privilégios para o exercício de

${ }^{7}$ Aviso é a designação oficial para a correspondência intraministerial, ou de ministros para outras autoridades.

${ }^{8}$ Documenta $\mathrm{n}^{\circ}$ 1, mar., 1962, p. 33-57. 
profissões liberais, o relator busca apoio na lei $\mathrm{n}^{0}$ 4.881.A/65, Estatuto do Magistério, ${ }^{9}$ pela qual ficava determinado que o CFE teria sessenta dias para conceituar e fixar as características da pós-graduação:

Art. 25. O Conselho Federal de Educação, no prazo de 60 (sessenta) dias, a contar da data da publicação da presente Lei, conceituará os cursos de pós-graduação e fixará as respectivas características.

Parágrafo único. Os cursos a que se refere o presente artigo poderão ser supridos, para efeito do disposto nesta Lei, por cursos de características equivalentes realizados, no exterior, em instituições de reconhecida idoneidade.

O parecer, após uma introdução referida ao aviso ministerial que solicitou a regulamentação da pósgraduação pelo CFE, possui sete tópicos: a origem da pós-graduação, sua necessidade, seu conceito, o exemplo da pós-graduação nos Estados Unidos, a pósgraduação na LDB de 1961, a pós-graduação e o Estatuto do Magistério, e a definição e caracterização da pós-graduação.

De acordo com esse parecer, a pós-graduação teria como objetivos a formação tanto de um corpo docente preparado e competente quanto a de pesquisadores de alto nível, e a qualificação profissional de outros quadros técnico-administrativos necessários ao desenvolvimento nacional. A pós-graduação deveria ter lugar na universidade, na medida em que é "integrante do complexo universitário, necessária à realização dos fins essenciais da universidade” (p. 73). Só excepcionalmente, mediante parecer autorizatório

9 Disponível em: <http://www.soleis.adv.br/ estatutomagisteriosuperior.htm>. Acesso em: maio de 2005. O parecer CFE nº 977 é de 3/12/1965 e a Lei do Estatuto é de 6/12/ 1965, mas a homologação e a publicação do parecer é posterior à lei. O próprio Newton Sucupira (1980, p. 15) reconhece essa cronologia: "logo após [o Estatuto] o Conselho confirmava o parecer CFE n 977/65, entendendo dar assim cumprimento ao que dispunha o citado art. 25”. De todo modo, a lei estabeleceu que, no plano de carreira, a pós-graduação seria levada em conta. do CFE, poderia haver pós-graduação em institutos isolados.

No parecer há o reconhecimento de que o sistema de ensino superior brasileiro ainda "não dispõe de mecanismos capazes de assegurar a produção de quadros docentes qualificados”. Aliás, o parecer, atento ao aviso ministerial que lembra "a imprecisão que reina entre nós sobre a natureza desses cursos” (p. 67), recorda que o conselheiro Clóvis Salgado já havia proposto uma indicação para que o CFE conceituasse pósgraduação, especialização, aperfeiçoamento e extensão de que tratava o art. 69, letra b, da LDB de 1961.

O relator aponta os vários modos de ser dessa modalidade de curso superior em países estrangeiros, como o francês, o alemão e, especialmente, o norteamericano. O parecer reserva um tópico específico para o paradigma norte-americano de pós-graduação:

[...] o Aviso Ministerial não se limita a solicitar uma interpretação, mas indica certos pontos básicos em função dos quais seria disciplinada a pós-graduação. Entende o sr. ministro que esses cursos, destinados à formação de pesquisadores e docentes para os cursos superiores, deveriam fazer-se em dois ciclos sucessivos, "equivalente aos de master e doctor da sistemática norte-americana. (p. 68, aspas do original) ${ }^{10}$

No tópico sobre a origem histórica da pós-graduação, o relator destaca que o nome e o sistema da

${ }^{10} \mathrm{O}$ famoso relatório Meira Mattos, produto do decreto $\mathrm{n}^{\mathrm{o}}$ 62.024 de 29/12/1967, apresentado ao ministro Tarso Dutra, já incorpora explicitamente, no nível universitário, o mestrado e o doutorado, voltados para os mais capacitados. Nesse caso, $\mathrm{Cu}-$ nha (1988) assinala a sincronia entre esse relatório e o parecer CFE $n^{\circ}$ 977/65. Sobre os relatórios Atcon e Meira Mattos, ver Fávero (1991). Também Nicolato (1986), estudando os convênios MEC/Agência Norte-Americana para o Desenvolvimento Internacional (USAID) desde 1965, demonstra como neles a institucionalização da pós-graduação e uma política de incentivo à pesquisa científica comparecem como propostas de formação de quadros de magistério e de desenvolvimento da pesquisa científica, apoiadas por sistemas de incentivos, entre os quais as bolsas de estudo. 
pós-graduação "tem sua origem próxima na própria estrutura da universidade norte-americana[...]”. Nela, pós-graduação volta-se para "estudos avançados, [...] estudos regulares com vista a um grau superior" (p. 69). Reconhece que o desenvolvimento desses estudos se impõe nos Estados Unidos como produto da influência germânica, instando a universidade a ir além da transmissão de conhecimento para se tornar um lugar de "elaboração de novos conhecimentos mediante a atividade de pesquisa criadora” (p. 69).

No item sobre a necessidade da pós-graduação, o relator a faz proceder "do extraordinário progresso do saber em todos os setores” (p. 70), pelo que a graduação - momento da formação básica superior não dá conta de acompanhar o ritmo das pesquisas, e nem seria razoável supor que todos os graduandos quisessem avançar da formação profissional básica para o pesquisador e o cientista. Usando da metáfora da infra (graduação) e da supra-estrutura (pós-graduação), diz o parecer:

[...] o desenvolvimento do saber e das técnicas aconselha introduzir na universidade uma espécie de diversificação vertical com o escalonamento de níveis de estudo que vão desde o ciclo básico, a graduação, até a pós-graduação. (p. 71)

Segundo o parecer, o sistema de ciclos sucessivos do ensino superior francês é similar a essa "diversificação vertical”. A pós-graduação torna-se, assim, na universidade moderna, cúpula dos estudos, sistema especial de cursos exigido pelas condições da pesquisa científica e pelas necessidades do treinamento avançado.

Como diz seu relator, o sistema brasileiro está em descompasso com o nível internacional:

Permanecemos até agora aferrados à crença simplista de que, no mesmo curso de graduação, podemos formar indiferentemente o profissional comum, o cientista e o tecnólogo. O resultado é que, em muitos setores das ciências e das técnicas, o treinamento avançado de nossos cientistas e especialistas há de ser feito em universidades estrangeiras. (p. 72)
E, para dotar o país de um processo sistemático de pós-graduação, é preciso urgência, "a fim de que possamos formar os nossos próprios cientistas e tecnólogos, sobretudo tendo em vista que a expansão da indústria brasileira requer número crescente de profissionais criadores, capazes de desenvolver novas técnicas e processos, e para cuja formação basta a simples graduação” (p. 72).

No tópico relativo ao conceito de pós-graduação, o relator precisa a natureza da mesma. Começa por distinguir a pós-graduação lato sensu e a stricto sensu. A primeira designa todo e qualquer curso que se segue à pós-graduação. E cita como exemplo os cursos de especialização que se destinam ao treinamento nas partes de que se compõe um ramo profissional ou científico a fim de formar o profissional especializado. Eles não visam abranger o campo total do saber em que se insere a especialidade. Já a pósgraduação stricto sensu realiza os fins essenciais da universidade por atender a estudos e pesquisas avançadas de modo regular, permanente e propiciando um grau acadêmico que deverá ser de uma alta competência científica em determinado ramo do conhecimento que, mesmo atuando em setores profissionais, tem objetivo essencialmente científico, enquanto a especialização tem sentido eminentemente práticoprofissional (p. 73-74).

O parecer, na seção subseqüente, apresenta a pósgraduação norte-americana como um exemplo:

Sendo, ainda, incipiente a nossa experiência em matéria de pós-graduação, teremos de recorrer inevitavelmente a modelos estrangeiros para criar nosso próprio sistema. O importante é que o modelo não seja objeto de pura cópia, mas sirva apenas de orientação. Atendendo ao que nos foi sugerido pelo Aviso ministerial, tomaremos como objeto de análise a pós-graduação norte-americana, cuja sistemática já provada por uma longa experiência tem servido de inspiração a outros países. (p. 74)

O parecer retém do sistema norte-americano os dois níveis (mestrado e doutorado), a distinção entre mestrado profissional e mestrado de pesquisa (M.A.), 
doutorado profissional e doutorado de pesquisa (Ph.D.), as áreas de concentração (major) e de domínio conexo (minor), a sistemática de cursos/créditos com grande flexibilidade, duração variável, exames de qualificação, domínio de língua estrangeira, acompanhamento dos estudos e pesquisas por um orientador e a exigência da dissertação para o mestrado e da tese para o doutorado.

Ainda comentando o modelo norte-americano relativo à seqüenciação mestrado/doutorado, diz o parecer:

Embora hierarquizados, são dois graus relativamente autônomos, isto é, o Ph.D. não exige necessariamente o M.A. como requisito indispensável. [...] de qualquer modo, o Mestrado se justifica como grau autônomo por ser um nível da pós-graduação que proporciona maior competência científica ou profissional para aqueles que não desejam ou não podem dedicar-se à carreira científica. (p. 75-76)

Além de requisitos severos de admissão, diz o relator:

[...] característica fundamental da pós-graduação norte-americana é que o candidato ao Mestrado e ao Doutorado, além da tese, dissertação ou ensaio, deverá seguir certo número de cursos, participar de seminários e trabalhos de pesquisa, e submeter-se a uma série de exames, incluindo-se as provas de língua estrangeira. (p. 77)

O parecer prossegue com o tópico sobre a pósgraduação na LDB de 1961. O autor comenta e interpreta o art. 69 dessa lei, dizendo que ele distingue, no ensino superior, a graduação, a pós-graduação e a especialização. Mas ela "não chega a determinar a natureza da pós-graduação. Se, por um lado, essa indefinição dá margem à iniciativa criadora das universidades”, a falta de tradição e experiência pode gerar “certa confusão na matéria” (p. 79). O relator assume sua função legal de conselheiro interpretando a lei nos limites da própria lei. A lei autoriza uma interpretação da pós-graduação como categoria própria, estabelecendo a necessidade de matrícula para os já graduados, o que denota a necessidade de esse nível ser de caráter permanente e regular. E, além da matrícula, os estabelecimentos podem fixar critérios próprios para os processos seletivos, pois "a pós-graduação por sua própria natureza implica alta seletividade intelectual” (p. 79-80). E o relator continua afirmando que, naquele momento, o CFE poderia definir oficialmente a pós-graduação, mas careceria de competência no sentido de uma regulamentação geral desses cursos, exceto quando capazes de "assegurar privilégio para o exercício de profissão liberal”, de acordo com o art. 70 da mesma lei (p. 81). Por isso, a fim de permitir ao CFE fazer essa regulamentação geral, o parecer apoia-se no Estatuto do Magistério:

[...] O controle dos cursos poderá ser feito por meio do reconhecimento, pelo menos à maneira de acreditation. $\mathrm{O}$ reconhecimento ou qualquer outro modo de controle que venha a disciplinar o processo de implantação dos cursos de pós-graduação, parece-nos de todo indispensável se considerarmos as condições de funcionamentos de nossas escolas superiores. A ser criada indiscriminadamente, a pósgraduação, na maioria dos casos, se limitará a repetir a graduação, já de si precária, com o abastardamento inevitável dos graus de mestre e doutor. (p. 81)

O simples fato de que um estabelecimento tenha seus cursos de graduação reconhecidos não significa que se encontra realmente habilitado para instruir a pós-graduação. Por isso mesmo, se quisermos evitar que a pós-graduação brasileira - essencial à renovação de nossa universidade seja aviltada em seu nascedouro, devemos estabelecer não somente princípios doutrinários mas critérios operacionais e normas que dirijam e controlem sua implantação e desenvolvimento. Daí a necessidade de que os cursos de pósgraduação sejam reconhecidos pelo Conselho. (p. 81)

Um primeiro elemento para esse controle seria a pós-graduação como prerrogativa das universidades, embora excepcionalmente pudesse ser levada adiante por uma instituição isolada.

A definição e as características do mestrado e do doutorado ocupam o ponto seguinte do parecer. 
A pós-graduação seria escalonada em dois níveis: mestrado, com duração mínima de um ano, e doutorado, com duração mínima de dois anos. Os programas teriam matérias próprias de uma área de concentração e outras específicas de domínio conexo. Duas fases caracterizariam a trajetória dos estudantes: aulas, seminários computados em um tempo de 360 a 450 horas, e exame geral, seguidos da investigação da qual resultará a dissertação ou tese. Contudo, “o mestrado não constitui obrigatoriamente requisito prévio para inscrição no curso de doutorado" (p. 83). ${ }^{11}$

No que concerne aos tipos de doutorado, o relator propõe para o doutorado de pesquisa "seja articulado com as quatro grandes áreas seguintes: Letras, Ciências Naturais, Ciências Humanas e Filosofia. Quanto aos doutorados profissionais teriam a designação do curso correspondente como, por exemplo, doutor em engenharia, doutor em medicina etc.”. Com relação ao mestrado, propõe "que o mestrado seja qualificado pela denominação do curso, área ou matéria correspondente” (p. 84).

Nas conclusões finais, em número de 16 , o relator explicita que os "cursos de pós-graduação devem ser aprovados pelo Conselho Federal de Educação para que seus diplomas sejam registrados no Ministério da Educação e possam produzir efeitos legais. Para isso o Conselho baixará normas fixando os critérios de aprovação dos cursos” (p. 86).

Comentando a organização da sistemática proposta para a pós-graduação no parecer, diz Bomeny (2001, p. 68): “Oferece, assim, o máximo de assistência e orientação ao aluno em seus estudos, sem prejuízo de sua liberdade de escolha e definição de sua própria agenda de investimento acadêmico”.

${ }^{11}$ Mesmo que as estruturas curriculares da pós-graduação não fossem, como na graduação, caracterizadas pelo currículo único, e internamente os cursos tivessem ampla liberdade, o modelo normatizado pelo parecer acaba formalizado em um modelo único. Nesse sentido, tem fim o sistema de doutorado "antigo", por exemplo, tal como praticado até então na USP.
Esse parecer, visto sempre como a base doutrinária e normativa da pós-graduação sistemática, será referência constante das outras normatizações que se lhe seguiram e para a solução de questões suscitadas na implantação dos programas e dos cursos.

Em uma artigo de 1980, Sucupira assim se expressa:

A pós-graduação sob a forma de cursos de mestrado e doutorado é fenômeno recente no ensino superior brasileiro. Mas seu aparecimento no cenário de nossa educação superior não é fruto de uma decisão intempestiva do CFE. É o resultado de um processo intimamente vinculado ao movimento de modernização da universidade brasileira, que teve seu início na década de 50. (p. 3)

Em outro trecho diz:

[...] o parecer n ${ }^{\circ}$ 977/65 não impôs um sistema de cursos estranho ao ensino superior brasileiro, mas veio ao encontro de experiências que já se generalizavam, embora vacilantes. Deu-lhes forma precisa, definindo uma sistemática que contribuiu decisivamente para o desenvolvimento da pós-graduação. Correspondeu, assim, a uma das exigências profundas do movimento da reforma universitária deflagrado na segunda metade da década de 50. (p. 17)

Nesse artigo, Sucupira procura preencher um certo vácuo que ficou no parecer, apresentando um histórico detalhado e documentado da pós-graduação entre 1931 e 1965. Nele, Francisco Campos, por exemplo, com sua reforma universitária de 1931, é visto como pioneiro da pós-graduação stricto sensu. Em que pese a procedência de tal histórico, o autor do artigo dá ao parecer nº 977/65 o lugar culminante e finalístico de um processo de amadurecimento da universidade brasileira.

\section{O impacto normativo do parecer}

O desejo de reforma universitária era um horizonte comum de muitos grupos sociais e de vários intelectuais desde os anos de 1950. O início dos anos 
de 1960 conhece os movimentos estudantis como protagonistas mobilizadores de uma reforma. Por sua vez, após a ditadura militar o Brasil teve uma eliminação prática de fóruns plurais e abertos de discussão dos problemas. Nesse sentido, o regime militar deu a sua resposta, na forma que lhe convinha, a esse longo movimento de busca de uma universidade a ser renovada. $^{12}$

Assim, em 2 de julho de 1968 foi constituído um Grupo de Trabalho da Reforma Universitária (GTRU) pelo decreto $n^{\circ}$ 62.937/68, “com a missão de estudar a reforma da Universidade brasileira, visando à sua eficiência, modernização, flexibilidade administrativa e formação de recursos humanos de alto nível para o desenvolvimento do país” (Reforma Universitária, 1968, p. 9). Entre tais postulações estava a criação dos cursos de pós-graduação, com a iniciativa do governo federal, de vez que os recursos para tal deveriam ser altos e o impacto dessa iniciativa estava muito além da capacidade isolada das universidades.

O relatório do GTRU afirma a urgência de se promover a consolidação dos cursos de pós-graduação, tendo em vista a necessidade do país de formar seus próprios cientistas, professores e técnicos que há muito recorriam às universidades estrangeiras. (Oliveira, 1995, p. 63)

O relatório acolhia a pós-graduação como prérequisito e co-requisito da universidade moderna cujos estudos e cujas pesquisas ajudariam tanto na formação de quadros quanto no incremento da pesquisa de alto nível. Também instava a urgência de uma política nacional de pós-graduação que centralizasse esforços e possibilitasse iniciativas adequadas. Do relatório surgiu a idéia dos centros regionais de pós-graduação, criados formalmente pelo decreto $\mathrm{n}^{\circ}$ 63.343/68. Por sua vez, o decreto $n^{0} 64.085 / 68$, dis-

${ }^{12}$ Muitos são os trabalhos sobre esse período, como, por exemplo: Cunha (1988), Rodrigues (1982), Germano (1993), Oliveira (1980) e Fávero (1996). põe sobre a instituição de uma comissão executiva para efetivar o Programa de Implementação dos Centros Regionais de Pós-Graduação instituídos pelo decreto $\mathrm{n}^{0}$ 63.343/68. $\mathrm{O}$ art. $1^{\circ}$ do decreto $\mathrm{n}^{0} 64.085$ diz, em sua letra d: "criar condições favoráveis ao trabalho científico, de modo a estimular a fixação dos cientistas brasileiros no país e incentivar o retorno dos que se encontram no estrangeiro". ${ }^{13}$

Tanto o parecer CFE $n^{\circ}$ 977/65 quanto a sugestão do GTRU serão referendados pela lei n ${ }^{0}$ 5.540/68, Lei de Reforma Universitária, de 28/11/1968, imposta pelo regime militar. ${ }^{14}$ De recorte centralizador, essa reforma se impôs em um clima avesso ao diálogo, próprio das ditaduras. Mesmo assim, a universidade foi adequadamente definida como instituição que se caracteriza pela indissociabilidade entre ensino, pesquisa e extensão.

Foi no regime militar que a pós-graduação se desenvolveu como patrimônio institucional da qualificação de docentes e como elemento fundamental da criação de um sistema nacional de ciência e tecnologia. Iniciam-se os cursos de pós-graduação no Rio de Janeiro (na então Universidade do Brasil, hoje UFRJ), em Viçosa (hoje Universidade Federal de Viçosa) e no Instituto de Tecnologia da Aeronáutica (ITA), inspirados no modelo norte-americano. Afinal, para o establishment político, a nossa fragilidade científica era vista mais como causa do "atraso" do que como conseqüência de uma dependência mais ampla e de

${ }^{13}$ Esses decretos foram publicados, respectivamente, na Documenta $\mathrm{n}^{\circ}$ 90, set., 1968, p. 105-107 e Documenta $\mathrm{n}^{\circ}$ 98, fev., 1969, p. 146-149. Os centros regionais de pós-graduação não chegaram a funcionar, e por isso o ministro Jarbas Passarinho, em 1973, nomeou comissão especial para formular uma nova política de pós-graduação. Daí resultou o decreto nº 73.411/74, complementar, publicado na Documenta $\mathrm{n}^{\circ} 158$, jan., 1974, p. 431-433.

${ }^{14}$ Comentando essa situação, Bomeny (2001, p. 69) analisa: “embora tenha sido escrito e aprovado no regime militar, o parecer não carregou para o seu autor a marca que nele seria impressa com o outro parecer [relalivo à Reforma Universitária] que viria redefinir a vida universitária brasileira”. 
uma exclusão secular em matéria de educação nacional, especialmente na escolarização básica.

Como diz Cunha (1988, p. 46):

Nos anos 60, apesar do regime autoritário em processo de acirramento (a lei $n^{\circ}$ 5.540/68 foi promulgada apenas um mês antes do Ato Institucional $n^{\circ}$ 5), houve uma busca de alianças com professores e pesquisadores, o que permitiu o desenvolvimento da pós-graduação e da pesquisa, diferenciando o panorama universitário brasileiro das demais ditaduras militares latino-americanas.

Por essa perspectiva contraditória, a institucionalização da pós-graduação no país caminhou no sentido de um Sistema Nacional de Pós-Graduação - cuja necessidade foi reforçada pela lei $\mathrm{n}^{\circ} 5.539 / 68,{ }^{15}$ que modifica o Estatuto do Magistério - e impôs a titulação pós-graduada stricto sensu como condição para a progressão na carreira docente das universidades.

A lei $n^{\circ}$ 5.540/68 atribuiu explicitamente ao CFE, no seu art. 24, a competência para conceituar a pósgraduação: “O Conselho Federal de Educação conceituará os cursos de pós-graduação e baixará normas gerais para a sua organização, dependendo sua validade, no território nacional, de os estudos nele realizados terem os cursos respectivos credenciados por aquele órgão”. Na verdade, tratava-se de formalizar em lei própria da educação o que já estava estabelecido em norma pelo parecer CFE no 977/65 do CFE e pelo Estatuto do Magistério.

A consolidação da pós-graduação acelerou quando a CAPES, o CNPq e outros órgãos públicos ficaram incumbidos pelo decreto-lei $n^{0} 464$, de 11/2/ 1969, art. 36, de promover a "formação e o aperfeiçoamento do pessoal docente de ensino superior” e compor para tanto uma política nacional e regional definida pelo CFE e promovida por uma comissão executiva.

O parecer do CFE no 77/69, também de autoria conselheiro Newton Sucupira, consoante o que já

${ }^{15}$ Documenta no 94, nov., 1968, p. 125-128. previa o parecer CFE $n^{0}$ 977/65, estabelece as normas regulatórias para o credenciamento dos cursos de pós-graduação stricto sensu, que deveriam obter a maioria dos votos dos conselheiros e serem homologados pelo ministro da Educação. ${ }^{16}$ Exigia-se um alto nível dos cursos de graduação na área, um corpo docente altamente qualificado, equipamentos, laboratórios, currículos, pesquisas e trabalhos de valor publicados em livros ou revistas científicas. Exigia-se também visitas in loco. Dentre as exigências desse parecer, pode-se ler no art. $8^{\circ}$, $\S 1^{0}$ :

Do candidato a professor em curso de pós-graduação será exigido o título de doutor, conferido por instituições idôneas, sendo ainda indispensável a apresentação de outros títulos que comprovem satisfatória especialização no campo de estudos a que se destina, tais como:

1) atividade científica, cultural ou técnica, constante de publicações feitas em livros ou periódicos conceituados, nacionais ou estrangeiros; [...].

O decreto $n^{\circ} 73.411$, de 4/1/1974, cria o Conselho Nacional de Pós-Graduação, de caráter interministerial, tendo à frente o ministro da Educação, o ministro do Planejamento, os presidentes do CNPq, da Financiadora de Estudos e Projetos (FINEP), do Banco Nacional de Desenvolvimento Econômico (BNDE), e cinco reitores. ${ }^{17}$

Logo após, o parecer CFE no 1683/74, ${ }^{18}$ também de autoria de Sucupira, diz:

${ }^{16}$ Normas do credenciamento dos cursos de pós-graduação, Documenta $\mathrm{n}^{\circ}$ 98, fev., 1969, p. 128-132. Atualmente o processo de credenciamento dos cursos de mestrado e doutorado segue os seguintes passos: a administração superior da universidade autoriza, a CAPES avalia e recomenda ou não, o Conselho Nacional de Educação credencia ou não e o ministro da Educação homologa ou não.

${ }^{17} \mathrm{O}$ decreto $\mathrm{n}^{\circ}$ 88.816, de 5/1/1982, extinguiu o Conselho Nacional de Pós-Graduação, vindo a CAPES a assumir, de modo ampliado, as funções desse conselho.

${ }^{18}$ Documenta ${ }^{\circ}$ 163, jun., 1974, p. 232-234. 
O parecer $77 / 69,{ }^{19}$ seguindo estritamente a doutrina do parecer $n^{\circ} 977 / 65$, distinguiu o doutorado acadêmico e o doutorado profissional, adotando nomenclatura diferente para cada uma das espécies. Assim, o art 13 , item $4^{\circ}$, estabelece que o doutorado acadêmico terá a designação das seguintes áreas: Letras, Ciências, Ciências Humanas, Filosofia e Artes. Os doutorados profissionais se denominam segundo os cursos de graduação correspondentes.

Quanto ao mestrado, o parecer aplica a mesma nomenclatura para o tipo acadêmico e o profissional, ao determinar que o mestrado será qualificado pelo curso de graduação, área ou matéria a que se refere.

Esse parecer postula nova redação para a segunda parte do inciso 4 do artigo 13 do parecer CFE $n^{\circ}$ 77, nos seguintes termos: "Os doutorados profissionais se denominam segundo os cursos de graduação correspondentes, com indicação, no diploma, da área de concentração seguida em cada caso. Aplica-se este último critério de designação aos mestrados acadêmicos e profissionais” (p. 232).

A visita institucional in loco por especialistas, para efeito de um credenciamento, foi normatizada pela resolução CFE $n^{\circ}$ 40/75. ${ }^{20}$

Art. $1^{\circ}$ A renovação do credenciamento dos cursos de pós-graduação em níveis de mestrado e de doutorado, prevista no artigo 17 do parecer $n^{\circ}$ 77/69, far-se-á mediante visita de inspeção à instituição responsável pelos cursos, realizada por comissão de especialistas designada pelo Presidente do CFE.

O parecer $n^{\circ} 8 / 75$, aprovado em 20 de janeiro de $1975^{21}$ pelo CFE, tendo como relator novamente o conselheiro Newton Sucupira, vai estabelecer as normas para a renovação periódica do credenciamento dos cursos de mestrado e de doutorado, a fim de assegurar o alto nível de funcionamento da pós-graduação.

\footnotetext{
${ }^{19}$ Documenta $\mathrm{n}^{\text {o }}$ 98, fev., 1969, p. 128-132.

${ }^{20}$ Documenta $^{\circ}$ 197, abr., 1977, p. 189-190.

${ }^{21}$ Documenta $n^{\circ} 170$, jan., 1975, p. 213-217.
}

Neste sentido, propomos que a renovação do credenciamento se faça por meio de uma visita de inspeção, à maneira da site visiting, utilizada com resultados satisfatórios no sistema de acreditation adotado nos Estados Unidos. Afinal de contas, o nosso credenciamento não é outra coisa que uma espécie de acreditation exercida pelo CFE. (Documenta $\mathrm{n}^{\circ} 170$, jan., 1975, p. 214)

Desse parecer resultou a resolução CFE $n^{0}$ 51/ $76,{ }^{22}$ que normatizou a renovação do credenciamento dos cursos de mestrado e de doutorado, prevista no art. 17 do parecer CFE nº 77/69. A renovação deveria conter, entre outras coisas, uma visita de inspeção à instituição realizada por especialistas de reconhecida competência na área, designada pelo CFE, que deveria seguir minucioso roteiro elencado na resolução.

Outro instrumento normativo será a resolução CFE $n^{0} 5 / 83,{ }^{23}$ que explicita as condições tanto para o credenciamento oficial quanto os pressupostos para que os diplomas de mestrado e doutorado passem a usufruir de validade em todo o território nacional, tudo com base no parecer CFE $n^{\circ}$ 977/65, como se pode ler nos dois primeiros artigos dessa resolução:

Art. $1^{\circ}$ Os cursos de pós-graduação, que conferem os graus de Mestre e Doutor, serão credenciados pelo CFE, nos termos da lei $n^{\circ} 5.540$, de 28 de novembro de 1968, para que seus diplomas gozem de validade em todo o território nacional.

Art. $2^{\circ} \mathrm{A}$ organização e o regime didático-científico dos cursos de pós-graduação seguirão a orientação do parecer $n^{\circ}$ 977/65, do CFE, consubstanciada nas seguintes normas básicas: [...].

O início da pós-graduação, como se vê, associava o Estado, o progresso da ciência e a busca de referências internacionais de conhecimento. O Estado impõe-se, ou melhor, vai impondo-se como o garantidor

${ }^{22}$ Documenta ${ }^{\circ} 190$, set., 1976, p. 392-394.

${ }^{23}$ Disponível em: <http://www.capes.gov.br/capes/portal/ conteudo/Resolucao_CFE_05_1983.pdf>.Acesso em: maio de 2005. 
de um desenvolvimento científico, visto como importante para a busca de uma autonomia nacional.

Essa forma inicial de presença institucional da pós-graduação nos anos de 1960 adquiriu força até nossos dias. Ela tem-se feito acompanhar de um quadro legal que comporta um sistema de autorização, credenciamento conduzido por pares, um sistema de financiamento (constante e oscilante ao mesmo tempo) e uma sistemática de bolsas para mestrado e doutorado. E, desde logo, fez e continua fazendo parte dessa sistemática um processo rigoroso e detalhado de avaliação de cursos e programas.

Desse modo, tivemos o I Plano Nacional de PósGraduação (I PNPG), relativo ao período 1975-1979, que deveria integrar-se a políticas de desenvolvimento social e econômico e ao II Plano Nacional de Desenvolvimento (II PND), por meio do Plano Setorial de Educação e Cultura (PSEC), e também ao II Plano Básico de Desenvolvimento Científico e Tecnológico (II PBDCT), no período 1975-1980.

O II PNPG (1982-1985) pretendeu articular-se com as diretrizes do II PND e do III PBDCT (19801985). Por sua vez, o III PNPG (1986-1989), produzido na denominada Nova República, teria que se compor com o I PND dessa etapa da política nacional.

Em que pese os esforços para a elaboração de um IV PNPG, o fato é que ele não ocorreu formalmente, e agora estamos, quarenta anos após o parecer CFE $n^{\circ}$ 977/65, dentro do V Plano Nacional de Pós-Graduação, para o período 2005-2010.

Ao lado desse processo, e complementar ao mesmo, o Brasil procurou estabelecer metas e objetivos para o sistema de pós-graduação. Desse modo, os planos nacionais de pós-graduação foram se sucedendo e, seja pela participação da comunidade científica, seja pelo seu caráter estratégico na produção do conhecimento científico, o fato é que esse nível do ensino superior tem sofrido menos do que a graduação em matéria de recuo do Estado no financiamento da educação.

[...] caso raro na história da educação brasileira, os planos nacionais de pós-graduação constituíram de fato um instrumento de política, isto é, as ações de governo guardaram suficiente coerência com os objetivos e metas declarados nos planos. (Martins, 1991, p. 99)

De todo modo, em matéria de política educacional, fica em aberto o peso relativo do parecer CFE $n^{\circ}$ 977/65 no conjunto das iniciativas do Estado. Afinal, a pós-graduação como uma estratégia de desenvolvimento em que a produção nacional de ciência e tecnologia era tida como imprescindível acabou tendo um suporte importante no próprio Estado.

A política de pós-graduação traduziu-se em realizações e demonstrações porque ela se impôs como uma ação deliberada do Estado em vista de sua implementação. Muito pouco pode ser atribuído a iniciativas pontuais de um ou outro organismo da sociedade civil ou a iniciativas endógenas das instituições particulares de ensino. Tanto é verdade que, além de uma estratégia vinculada ao desenvolvimento tecnológico autônomo, as políticas de pós-graduação estiveram sempre ligadas aos órgãos decisórios da área federal. É dentro desse contexto que o parecer deve ser analisado e ponderado.

O parecer CFE no 977/65 é texto fundador da pós-graduação sistemática no Brasil e, após ele, parece não haver nenhum outro texto que articule doutrina e normatização sobre o assunto com tanto impacto sobre esse nível da educação superior no Brasil.

Diante de tal permanência e diante da ausência de outro texto doutrinário tão marcante como ele, mesmo havendo passado por governos de matizes tão diferentes, o parecer $n^{\circ}$ 977/65 leva a pensar. O parecer é acoimado de ser devedor do modelo norte-americano de pós-graduação e do próprio modelo de desenvolvimento da ditadura. Mas será isso que revela a trajetória da pós-graduação? É bem mais provável que estejamos diante de uma situação heteróclita, cujo fruto procede de vários cruzamentos, inclusive da atuação da própria comunidade acadêmica. E o processo real da pós-graduação não se deu exatamente do modo como se previa. Ao formar intelectuais, acadêmicos e pesquisadores de alto nível, com circulação nacional e internacional, não 
sugere uma tensão entre objetivos proclamados e resultados inesperados?

Ou, como diz Saviani (2005, p. 37):

Um outro aspecto importante da política educacional dos anos de 1970 refere-se à pós-graduação, regulada pelo parecer 977/65, do CFE. Embora implantada segundo o espírito do projeto militar do "Brasil Grande” e da modernização integradora do país ao capitalismo de mercado associado-dependente, a pós-graduação se constituiu num espaço privilegiado para o incremento da produção científica e, no caso da educação, também para o desenvolvimento de uma tendência crítica que, embora não predominante, gerou estudos consistentes sobre cuja base foi possível formular a crítica e a denúncia sistemática da pedagogia dominante, alimentando um movimento de contra-ideologia.

De qualquer modo, chama a atenção a longa permanência referencial do parecer $n^{\circ}$ 977/65. Um texto clássico, segundo Ítalo Calvino, é o que continua sendo uma referência e que não cessa de expressar o que tem a dizer, mesmo que haja sido escrito em época diferente daquela que vivemos. Um tal texto continua sendo um convite para repensar projetos existentes e servir de ponto e contraponto para projetos alternativos. Transcendendo os limites do seu tempo, ele suscita leituras que atualizam, para nossa época, aspirações de forças sociais que lutam por novas realidades.

Seria o caso de se perguntar: estamos diante de um texto clássico?

CARLOS ROBERTO JAMIL CURY, doutor em história e filosofia da educação pela Pontifícia Universidade Católica de São Paulo (PUC-SP), é professor emérito da Universidade Federal de Minas Gerais (UFMG) e docente na Pontifícia Universidade Católica de Minas Gerais (PUC-MG), na qual atua no mestrado em educação. Publicações mais importantes: Ideologia e educação brasileira: católicos e liberais (São Paulo: Cortez/Autores Associados, 1988, 4ª ed.); Educação e contradição: elementos metodológicos para uma teoria crítica do fenômeno educativo (São Paulo: Cortez/Autores Associados, 1989); Cidadania republicana e educação: Governo Provisório do Mal. Deodoro e Con- gresso Constituinte de 1890-1891 (Rio de Janeiro: DP\&A, 2001); Legislação educacional brasileira (Rio de Janeiro: DP\&A, 2001). Pesquisa atual: O (antigo) Conselho Nacional de Educação (CNE): 1931-1937.E-mail: crjcury.bh@terra.com.br

\section{Referências bibliográficas}

BEIGUELMAN, Bernardo, (1997). Reflexões sobre a pós-graduação brasileira. In: PALATNIK, Marcos (org.) Pós-graduação no Brasil. Rio de Janeiro: Editora da Universidade Federal do Rio de Janeiro, p. 33-47.

BOMENY, Helena, (2001). Newton Sucupira e os rumos da educação superior. Brasília: Paralelo 15 e CAPES.

BRASIL, Ministério da Educação e Cultura, Secretaria de Educação Superior/Coordenação de Aperfeiçoamento de Pessoal de Nível Superior, (1975). I Plano Nacional de Pós-Graduação: 1975-1979. Brasília: MEC/SESU/CAPES.

(1982). II Plano Nacional de Pós-Graduação: 19821985. Brasília: MEC/SESU/CAPES.

(1986). III Plano Nacional de Pós-Graduação: 1986-1989. Brasília: MEC/SESU/CAPES.

CARVALHO, Janete Magalhães, (1992). A formação do professor pesquisador em nível superior no Brasil: análise histórica do discurso do governo e da comunidade acadêmico-científica. Tese de doutorado. Faculdade de Educação da Universidade Federal do Rio de Janeiro.

CUNHA, Luiz Antônio, (1988). A universidade reformanda. Rio de Janeiro: Francisco Alves.

CURY, Carlos Roberto Jamil, (2004a). Qualificação pós-graduada no exterior. In: ALMEIDA, Ana Maria F., CANÊDO, Letícia Bicalho, GARCIA, Afrânio et al. Circulação internacional e formação intelectual das elites brasileiras. Campinas: UNICAMP, p. 107-143.

, (2004b). Graduação/pós-graduação: a busca de uma relação virtuosa. Educação e Sociedade, Campinas, CEDES, v. $25, \mathrm{n}^{\circ} 88$, especial out., p. 777-793.

, (2005). Bases legais da pós-graduação. Texto para o V Plano Nacional de Pós-Graduação: 2005-2010. Disponível em: <http://www.mec.gov.br/acs/pdf/DocFinal_PNPG04.pdf>. Acesso em: maio.

FÁVERO, Maria de Lourdes de Albuquerque, (1991). Da universidade "modernizada" à universidade disciplinada: Atcon e Meira Mattos. São Paulo: Cortez; Campinas: Autores Associados. 
(org.) (2000a). Universidade do Brasil II: guia dos dispositivos legais. Rio de Janeiro: Editora UFRJ; Brasília: COMPED/MEC/INEP.

(2000b). Universidade e poder: análise crítica/fundamentos históricos: 1930-1945. Brasília: Plano.

FÁVERO, Osmar, (1996). A educação no Congresso Constituinte de 1966-67: contrapontos. In: FÁVERO, Osmar (org.). A educação nas constituintes brasileiras: 1823-1988. Campinas: Autores Associados, p. 241-253.

GERMANO, José Willington, (1993). Estado militar e educação no Brasil: 1964-1985. São Paulo: Cortez; Campinas: Ed. UNICAMP.

HORTA, José Silvério Baía, (1982). Liberalismo, tecnocracia e planejamento educacional no Brasil. São Paulo: Cortez; Campinas: Autores Associados.

LOBO, Yolanda, (1991). A construção e definição de políticas de pós-graduação em educação no Brasil: a contribuição de Anísio Teixeira e Newton Sucupira. Tese de doutorado. Departamento de Educação da Pontifícia Universidade Católica do Rio de Janeiro.

MANIFESTO DA FUNDAÇÃO DA ESCOLA DE SOCIOLOGIA E POLÍTICA DE SÃO PAULO, (1933). In: FÁVERO, Maria de Lourdes de A., (org.) (2000). Universidade e poder: análise crítica/fundamentos históricos: 1930-1945. Brasília: Plano, p. $199-204$

MARTINS, Ricardo de C. Rezende, (1991). A pós-graduação no Brasil: uma análise do período 1970-90. Educação Brasileira, Brasília, CRUB, v. 13, nº 27, jul.-dez., p. 93-119.

, (1999a). A capacitação de docentes no sistema universitário brasileiro: políticas, estratégias, problemas e resultados. Estudos e Debates, Brasília, CRUB, nº 19, mar., p. 83-112.

(1999b). A pós-graduação no Brasil: situação e perspectivas. Sociedade e Estado, Brasília, v. XIV, no 2, jul.-set., p. 273-297.

NICOLATO, Maria Auxiliadora, (1986). A caminho da lei $n$. 5.540/68: a participação de diferentes atores na definição da
Reforma Universitária. Dissertação de mestrado. Faculdade de Educação da Universidade Federal de Minas Gerais, v. II.

OLIVEIRA, Betty Antunes, (1980). O Estado autoritário brasileiro e o ensino superior. São Paulo: Cortez; Campinas: Autores Associados.

OLIVEIRA, Fátima Bayma de, (1995). Pós-graduação: educação e mercado de trabalho. Campinas: Papirus.

REFORMA UNIVERSITÁRIA, (1968). Relatório do Grupo de Trabalho criado pelo decreto $n^{\circ}$ 62.937/68. Brasília: Ministério da Educação e Cultura, Ministério do Planejamento e Coordenação Geral, Ministério da Fazenda.

REZENDE, Sérgio M., (1997). Pós-graduação e pesquisa no Nordeste. In: PALATNIK, Marcos (org.). A pós-graduação no Brasil. Rio de Janeiro: Editora da UFRJ, p. 109-131.

ROCHA NETO, Ivan, (1991). A universidade pública, a formação de quadros e o país. In: VELLOSO, Jacques (org.). Universidade pública: política, desempenho e perspectivas. Campinas: Papirus, p. 77-105.

RODRIGUES, Neidson, (1982). Estado, educação e desenvolvimento econômico. São Paulo: Cortez; Campinas: Autores Associados.

SANTOS, Cássio Miranda dos, (2003). Tradições e contradições da pós-graduação no Brasil. Educação e Sociedade, Campinas, CEDES, v. 24, nº 83, p. 627-641.

SAVIANI, Dermeval, (2005). A política educacional no Brasil. In: CÂMARA BASTOS, Maria Helena, STEPHANOU, Maria (orgs.). Histórias e memórias da educação no Brasil - v. III, séc. XX. Petrópolis: Vozes, p. 30-39.

SUCUPIRA, Newton, (1980). Antecedentes e primórdios da pósgraduação. Fórum Educacional, Rio de Janeiro, Fundação Getúlio Vargas, ano 4, nº 4, out.-dez., p. 3-18.

Recebido em março de 2005 Aprovado em maio de 2005 


\section{Resumos/Abstracts}

Carlos Roberto Jamil Cury

Quadragésimo ano do parecer CFE n $^{0}$ 977/65

$\mathrm{O}$ artigo pretende, por ocasião do quadragésimo ano do parecer CFE n ${ }^{\circ} 977 /$ 65, mostrar sua presença pioneira na pós-graduação brasileira, sua importância e seu impacto no sistema nacional de pós-graduação. Nesse sentido, propôs-se a analisá-lo em seu contexto de época, a expor seus principais movimentos e a analisar seus desdobramentos normativos. À vista da inexistência de outro parecer normativo sobre a pós-graduação, nesses 40 anos, interroga-se sobre a natureza do mesmo em relação a sua duração no tempo.

Palavras-chave: pós-graduação no Brasil; ensino superior; parecer CFE $n^{\circ}$ 977/65

The fortieth anniversary of the publication of the report $n^{\circ} 977 / 65$ of the Federal Council of Education The article, commemorating the $40^{\text {th }}$ anniversary of the publication of the National Council of Education report $n^{\circ}$ 977/65, seeks to show its pioneering presence in brazilian postgraduate studies and its importance and impact on the national system of postgraduate studies. In this sense, the article proposes to analyse the report within the context of the period, explain its principal advances and analyse its normative implications. Given the absence of any other normative report on postgraduate studies in the last 40 years, it questions the nature of the text with relation to its duration over time. Key-words: postgraduate studies in Brazil; higher education; report CFE $n^{\circ}$ 977/ 65 